\title{
Uso del propranolol como modulador de la memoria y el aprendizaje en modelos animales
}

\author{
Use of Propranolol as a modulator of Learning and memory \\ in Animal models \\ Uso do propranolol como modulador da memória \\ e a aprendizagem em modelos animais
}

\author{
Mariana Psyrdellis*, Nadia Romina Justel ${ }^{*}$ \\ "Laboratorio de Psicología Experimental y Aplicada (PSEA), Instituto de Investigaciones Médicas (IDIM), \\ Consejo Nacional de Ciencia y Tecnología (CONICET), Buenos Aires, Argentina.
}

Doi: http://dx.doi.org/10.12804/ap134.3.2016.10

\section{Resumen}

El propranolol es un antagonista $\beta$-adrenérgico no selectivo de los receptores adrenérgicos $\beta 1$ y $\beta 2$. El rol de este sistema de neurotransmisión sobre la memoria ha sido demostrado en diversas investigaciones, ya sea tanto en la fase de codificación, consolidación y evocación como en la reconsolidación. El objetivo de este trabajo es realizar una revisión sobre los efectos de este $\beta$-bloqueante en diversos aprendizajes con paradigmas animales, entendiendo por medio de esto las implicaciones del sistema noradrenérgico en los procesos de memoria. El fármaco muestra resultados particulares dependiendo del momento de su aplicación y del diseño experimental empleado. En el trabajo se discuten los efectos de la droga sobre las distintas fases de la memoria en paradigmas animales con contenido espacial, estímulos gustativos y aversivos, con entrenamientos complejos, y con aprendizajes de un solo ensayo.

Palabras clave: propranolol; memoria; aprendizaje; modelos animales.

\section{fibstract}

Propranolol is a non-selective $\beta 1$ and $\beta 2$ adrenergic antagonist. The role of this system in memory neurotransmission has been shown in various studies, either in the encoding, consolidation, recall and reconsolidation process. The aim of this work is to review the effects of this $\beta$-blocker in different animal's paradigms, studding the implications of the noradrenergic system in memory processes. The drug shows individual results depending on the time of application and the experimental design employed. There were analyzed the effects of the drug

* Mariana Psyrdellis, Nadia Romina Justel, Laboratorio de Psicología Experimental y Aplicada (PSEA), Instituto de Investigaciones Médicas (IDIM), Consejo Nacional de Ciencia y Tecnología (CONICET), Buenos Aires, Argentina.

La correspondencia relacionada con este artículo debe ser dirigida a Mariana Psyrdellis, Laboratorio de Psicología Experimental y Aplicada (PSEA), Instituto de Investigaciones Médicas (IDIM/CONICET), Combatientes de Malvinas 3150 1428, Buenos Aires, Argentina. Correo electrónico: marianapsyrdellis@hotmail.com

Cómo citar este artículo: Psyrdellis, M. \& Justel, N. R. (2016). Uso del propranolol como modulador de la memoria y el aprendizaje en modelos animales. Avances en Psicología Latinoamericana, 34(3), 565-585. doi: http://dx.doi.org/10.12804/ ap134.3.2016.10 
on the different phases of memory, in animals models with spatial task, with aversive or taste stimuli, with complex training or with single trial learning.

Keywords: propranolol; memory; learning; animal models.

\section{Resumo}

O propranolol é um antagonista $\beta$-adrenérgico não seletivo dos receptores adrenérgicos $\beta 1$ y $\beta 2$. $O$ rol deste sistema de neurotransmissão sobre a memória tem sido demonstrado em diversas pesquisas, seja tanto na fase de codificação, consolidação, evocação, seja quanto reconsolidação. O objetivo deste trabalho é realizar uma revisão sobre os efeitos deste $\beta$-bloqueante em diversas aprendizagens com paradigmas animais, entendendo por meio disto as implicações do sistema noradrenérgico nos processos da memória. $\mathrm{O}$ fármaco mostra resultados particulares dependendo do momento da sua aplicação e do desenho experimental empregado. No trabalho discutem-se os efeitos da droga sobre as distintas fases em paradigmas animais com conteúdo espacial, estímulos gustativos e aversivos, com treinos complexos e com aprendizagens de um só ensaio.

Palavras-chave: propranolol; memória; aprendizagem; modelos animais.

La memoria puede considerarse una adaptación biológica que permite a los organismos usar los aprendizajes pasados para ajustar su comportamiento a las demandas actuales del ambiente. La formación de memorias implica cambios en la funcionalidad y estructura de diversas áreas cerebrales involucradas, por ejemplo hipocampo, locus coeruleus, núcleos basales, corteza frontal, entre otros, debido a la acción de los distintos sistemas de neurotransmisión (McGaugh, 2000). Frente a un estímulo que será aprendido, se desencadenan cascadas neurobiológicas que afectan la conectividad, actividad, reactividad y plasticidad neuronal, modificando tanto los componentes intrínsecos de las células como las sinapsis (Aston, Chiang, \&
Alexinsky, 1991). Uno de los sistemas de neurotransmisión que se encuentran involucrados en la memoria es el noradrenérgico (NA), que permite y acentúa la actividad sináptica que producen los estímulos novedosos o significativos y con contenido emocional (Sara, Vankov, \& Hervé, 1994).

El propranolol (C16H21NO2) es un antagonista $\beta$-adrenérgico no selectivo, por lo cual bloquea la acción de la noradrenalina en los receptores adrenérgicos $\beta 1$ y $\beta 2$. Este fármaco, que implica al metabolismo hepático y es de acción periférica, posee una vida media de 4-5 horas y una biodisponibilidad del 26\% (WHO, 2013). Es utilizado principalmente como ansiolítico en situaciones puntuales, como para el tratamiento de picos de ansiedad con predominio de sintomatología periférica (sudor, temblor, taquicardia, etc.) y para el síndrome de retirada de opiáceos (Fernández Teruel, 2008). Además, es empleado como una herramienta de segunda elección frente al síndrome de migrañas agudas en niños (Suresh \& Steven, 2003).

Si bien el propranolol es un antagonista de los receptores $\beta$-adrenérgicos, también se reportó su influencia sobre los receptores serotoninérgicos (Giacovich \& Enero, 1984; Middlemeis, 1984; Prut \& Belzung, 2003; Sprouse \& Aghajanian, 1986). Este sistema de neurotransmisión, además de controlar la presión sanguínea, se encuentra involucrado tanto en aprendizajes asociativos y no asociativos, como en la formación de memorias (Cassel, 2010; Zhang et al., 2013).

Por ende, debido a la importancia de los sistemas de neurotransmisión sobre los que actúa el propranolol, resulta pertinente interrogarse acerca del efecto de esta droga sobre la memoria y el aprendizaje. Por otra parte, el empleo de modelos animales es un modo eficaz para evaluar dichos constructos. En investigación, estos diseños comparados ofrecen numerosas ventajas ya que permiten evaluar las variables como procesos conductuales determinados, entendiendo científicamente sus principios y mecanismos (Hunziker \& Pérez-Acosta, 2001). 
Por lo tanto, el objetivo de este trabajo es realizar una revisión sobre los efectos de este $\beta$-bloqueante en diversos aprendizajes con paradigmas animales, entendiendo por medio de esto las implicaciones del sistema noradrenérgico en los procesos de memoria.

\section{Método}

Se realizó una búsqueda bibliográfica en las bases de datos indexadas, tales como ScienceDirect y Pubmed, de marzo a diciembre del 2014, con las palabras claves "propranolol-memoria", en inglés propranolol-memory. En primer término se obtuvieron un total de 5228 artículos. Luego, se ajustó la búsqueda incorporando la palabra clave "modelo animal", en inglés animal model, lo que arrojó un total de 3562 resultados. De esos artículos, se seleccionaron los más pertinentes, teniendo en cuenta la relevancia con el objetivo planteado y las fechas de publicación. En total, se preseleccionaron 200 artículos y se analizaron sus referencias para orientar una tercera fase de búsqueda. Los manuscritos relevantes forman parte de este trabajo.

\section{Efectos del propranolol sobre la memoria}

Un proceso óptimo de almacenamiento de experiencias necesita equilibrar la capacidad de formar asociaciones complejas que puedan permanecer $\sin$ cambios durante muchos años, con aspectos dinámicos vinculados con la plasticidad para modificar esos aprendizajes y el adecuado uso de la información disponible (Robinson, Ross, \& Franklin, 2011). Para ello, es necesario comprender los distintos procesos de memoria o fases que involucra la formación de los trazos mnémicos.

En primera medida, la memoria implica el ingreso o entrada de los estímulos, junto con la correcta organización de los ítems percibidos, lo que es entendido como la fase de codificación. En segundo lugar, la consolidación de la memoria es la instancia mediante la cual memorias lábiles se vuelven persistentes y se almacenan. Luego, es necesario un proceso de evocación, en el que se hace uso del aprendizaje almacenado. Los tratamientos experimentales que se apliquen antes de la adquisición de un entrenamiento estarán afectando la codificación, inmediatamente después serán relevantes para la consolidación, y si se emplean antes de la evaluación de esa información almacenada (test), se vinculan con la evocación (Justel \& Psyrdellis, 2014).

Tradicionalmente, se consideró a estas tres fases las relevantes para la formación de recuerdos, sin embargo, múltiples estudios dan cuenta de que es posible manipular memorias ya formadas mediante la fase que hoy día se conoce como reconsolidación. Esta última implica un periodo de labilización de memorias ya formadas, por medio de un proceso de reactivación en el que se vuelven a presentar claves que ya habían estado presentes en la consolidación, haciendo susceptibles de manipulación dichos aprendizajes (Debiec \& Ledoux, 2004). Los tratamientos experimentales que se apliquen luego de la reactivación permiten arrojar información acerca del proceso de reconsolidación (ver figura 1).

Cada proceso implica cascadas de activación neuromoleculares particulares (McGaugh, 2000). La noradrenalina, siendo uno de los moduladores neurales más importantes en el cerebro, está implicada en la regulación de estos procesos (Ferry, Roozendaal, \& McGaugh, 1999; Gibbs \& Summers, 2002; McGaugh, Cahill, \& Roozendaal, 1996). Por ejemplo, los $\beta$-adreno-receptores en el área CA1 del hipocampo participan en los mecanismos de potenciación de largo plazo (Katsuki, Yukitoshi, \& Zorumski, 1997; Thomas, Moody, Makhinson, \& O’Dell, 1996; Winder et al., 1999). Por esto, destacando las particularidades de cada proceso de memoria y la interacción noradrenérgica, resulta relevante indagar los efectos del propranolol sobre cada instancia por separado. 


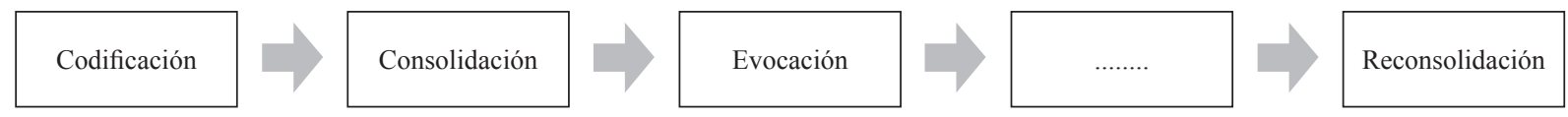

Figura 1. Representación de los procesos de memoria

\section{Propranolol y codificación de la memoria}

Tal como se definió, para adquirir un aprendizaje es necesario el ingreso y la correcta organización de un estímulo (McGaugh, 2000). En esta fase son relevantes los procesos psicológicos y la adecuada percepción de un estímulo, así como el estado fisiológico de los sujetos, lo que puede convertirse en una variable inespecífica que altere los resultados experimentales. Los tratamientos que permiten arrojar conclusiones acerca de la codificación de la memoria implican la aplicación de la variable farmacológica antes de la fase de entrenamiento de un paradigma (ver figura 2).

En primer lugar, puede considerarse el paradigma de aversión al sabor, diseño que permite evaluar la constitución de memorias aversivas. Los roedores tienen la tendencia natural a consumir en poca cantidad soluciones novedosas (neofobia), sin embargo, si no se producen consecuencias negativas cuando ésta es presentada por segunda vez, el animal tenderá a aumentar su consumo (atenuación de la neofobia). En el entrenamiento de aversión al sabor, si la primera ingesta es seguida de una consecuencia negativa, como la producción de malestar debido a la administración de una sustancia tóxica (e.g. la administración de litio), se genera una asociación entre la sustancia novedosa y la consecuencia física negativa (Justel \& Ruetti, 2012). En la fase de testeo, en la que se presenta la solución por segunda vez, es esperable un menor consumo de ésta. Se ha demostrado que infusiones locales de una dosis alta de propranolol (20 $\mu \mathrm{g} / 0,5 \mu \mathrm{l})$ deterioraron el aprendizaje de aversión al sabor, pero dosis bajas ( 1 o $2,5 \mu \mathrm{g} / 0,5 \mu \mathrm{l})$ no tuvieron efecto en la amígdala baso lateral y en el cortex insular (Berman, Hazvi, Neduva, \& Dudai, 2000; Miranda, Rodríguez-García, Reyes-López, Ferry, \& Ferreira, 2008). Este paradigma consistió en brindarles acceso a ratas a $10 \mathrm{ml}$ de solución de sacarosa al 0,1\% durante 15 minutos, luego de un primer ensayo de línea base con agua. Treinta minutos más tarde los animales fueron inyectados por vía intraperitoneal (ip) con litio. Inmediatamente antes de recibir acceso a la solución de sacarosa, se administró la droga o el vehículo (en las dosis previamente mencionadas). Encontraron que el grupo experimental que recibió el propranolol en dosis bajas consumió significativamente menos la solución de sacarosa al igual que el grupo inyectado con vehículo, por lo cual este resultado permite inferir que no hay efecto de la droga. Sin embargo, el empleo de una dosis más elevada en las mismas condiciones mostró ser efectivo para dañar este aprendizaje (Berman et al., 2000), lo que permite pensar que el sistema noradrenérgico se encuentra

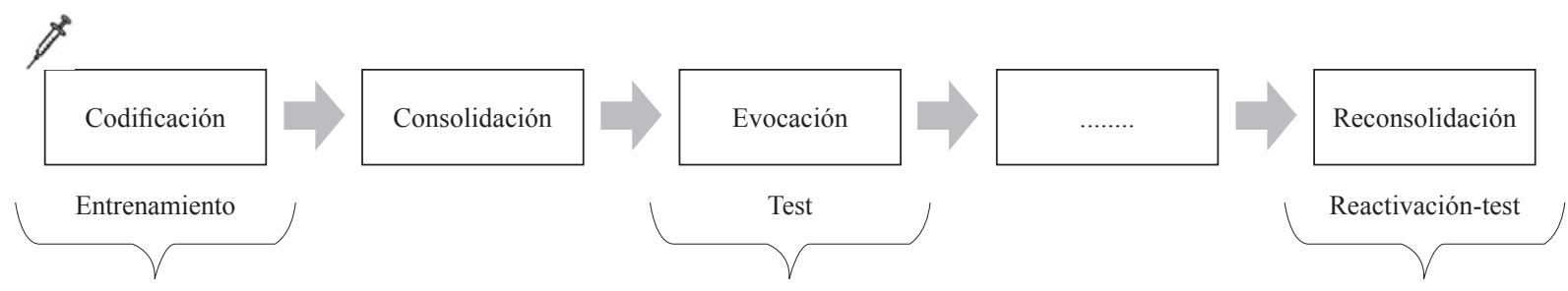

Figura 2. Representación del momento de aplicación de los tratamientos que afectan la adquisición de una memoria. Implican una administración de la manipulación experimental prentrenamiento 
involucrado en la codificación de este paradigma formador de memorias aversivas y emocionales de manera dosis dependiente.

Por otro lado, puede evaluarse el rol del propranolol sobre la codificación en paradigmas de memoria espacial. Para ello, se utiliza, por ejemplo, el laberinto en forma de $Y$, el cual es un dispositivo que consiste en tres brazos, uno es el de salida y los otros dos son iguales entre sí. Durante el entrenamiento, uno de los brazos iguales permanece inaccesible. En la fase de testeo, ambos brazos se encuentran abiertos, y debido a la tendencia de los roedores a explorar lo novedoso es esperable que exploren más el brazo no conocido. Con el objetivo de determinar los parámetros de la droga sobre este paradigma, Sun, Mao, Wang y Ma (2011) inyectaron a ratones con propranolol $(2,10$ y $20 \mathrm{mg} / \mathrm{kg}$, ip) 15 minutos antes del entrenamiento. Encontraron que las dos dosis elevadas de la droga deterioraron la memoria, es decir que los roedores exploraron por igual tanto el brazo conocido como el novel. Dado que la dosis de $2 \mathrm{mg} / \mathrm{kg}$ actuó igual que el vehículo, se concluye que hay un efecto dosisdependiente relativo al momento de administración de la droga, similarmente a lo que sucede con la memoria de aversión al sabor.

Por otra parte, se ha demostrado que la novedad puede generar efectos diferenciales sobre los aprendizajes dependiendo del momento de su aplicación (Justel \& Psyrdellis, 2014). A su vez, la exploración de la novedad está acompañada por un aumento en el hipocampo y núcleo accumbens de la actividad noradrenérgica (Sun et al., 2011; Tuinstra \& Cools, 2000), por lo cual es pertinente preguntarse acerca de la acción del propranolol en el fenómeno. Justel, Psyrdellis, Pautassi y Mustaca (2014) encontraron que el propranolol (4,5 mg/kg, ip) puede deteriorar la adquisición de la novedad como modulador de la memoria de la frustración, mostrando efectos particulares según el ensayo en el que se aplique el tratamiento novedoso. Para ello emplearon el paradigma de contraste sucesivo negativo consumatorio ( $\mathrm{CSNc}$ ), el cual es un modelo animal para el estudio de la devaluación de incentivos y frustración. Éste consiste en darles a las ratas una solución azucarada al $32 \%$ por 5 ensayos diarios, luego de lo cual se devalúa la concentración y pasan a recibir 4\% de solución azucarada por 3 ensayos más. De este modo, la discrepancia entre lo que esperan recibir y lo que encuentran genera una disminución abrupta del consumo en sujetos que siempre consumieron la solución al $4 \%$. Si previamente al primer contacto con la solución menos apetitiva (E1) los sujetos exploran un campo abierto (CA) por 5 minutos, se genera un deterioro sobre la memoria de la frustración, evidenciada en un mayor consumo de la solución de 4\%. Se observó el patrón contrario cuando el CA es aplicado de modo previo al segundo ensayo (E2), ya que disminuye el consumo de la solución de $4 \% \mathrm{y}$, por ende, genera una acentuación de la frustración. Se reportó que la inyección de la droga 15 minutos antes del CA en el E1 atenúa el fenómeno de deterioro de la frustración. En el E2, la aplicación farmacológica previa al CA genera un deterioro del efecto de la novedad sobre el CSNc, que en este ensayo se refiere a una acentuación de la frustración. Esto permite concluir que el sistema NA y el efecto del propranolol están presentes en la adquisición de la novedad en el E1 y en el E2 de frustración (Justel et al., 2014).

Por todo lo expuesto, puede concluirse que el sistema NA se encuentra involucrado en la codificación del laberinto en $\mathrm{Y}$, en la codificación de la novedad como modulador de la frustración en el paradigma consumatorio de CSN y en el paradigma de aprendizaje aversivo al sabor. Sin embargo, puede pensarse que la literatura sobre el efecto de este antagonista sobre paradigmas experimentales en animales es escasa, por lo que se considera que es importante desarrollar investigaciones al respecto. Cabe destacar que esto puede deberse a que dicha fase resulta difícil de aislar, ya que al aplicar variables intervinientes antes de cualquier entrenamiento se pueden estar afectando también los posteriores procesos del aprendizaje. 


\section{Propranolol y consolidación de la memoria}

Los tratamientos que permiten arrojar conclusiones acerca de la consolidación de la memoria implican la aplicación de la variable farmacológica de forma inmediatamente posterior a la fase de entrenamiento de un paradigma experimental (ver figura 3). Los datos en relación con el efecto del propranolol sobre esta instancia son particulares dependiendo del modelo animal empleado.

El paradigma de condicionamiento de miedo es un modelo animal que permite evaluar la respuesta conductual de los animales frente a un aprendizaje aversivo. Consiste en exponer a los sujetos, en una caja de condicionamiento, a la presencia de un estímulo neutro que no genera ninguna activación fisiológica particular, por ejemplo un tono. Después se presenta dicho tono simultáneamente con un choque eléctrico, el cual produce la respuesta incondicionada o innata de sobresalto y miedo. Luego, la sola presencia del tono resulta un predictor del choque eléctrico, produciendo la respuesta de sobresalto y miedo, medido por medio de la conducta de congelamiento o inmovilidad (freezing) que presentan los animales. Berlau y McGaugh (2006) expusieron a los sujetos en la fase de entrenamiento a un tono que fue apareado a un choque eléctrico moderado, seguido por la administración de propranolol mediante infusiones en la corteza media prefrontal $(2,5 \mu \mathrm{g} / \mu \mathrm{l})$. Luego de 48 horas, evaluaron la respuesta de inmovilidad de las ratas frente a la presencia del tono solo. Hallaron que la droga produjo efectos amnésicos en estas condi- ciones, es decir que los animales no presentaban sobresalto ante el tono que predecía el choque (Berlau \& McGaugh, 2006; Mueller, Porter, \& Quirk, 2008). Sin embargo, Debiec y Ledoux (2004), en el mismo diseño, administraron propranolol por dos vías: infusiones intraamigdalinas en núcleos basales y laterales $(2,5 \mu \mathrm{g} / \mu \mathrm{l})$, y por medio de inyecciones sistémicas ( $1 \mathrm{ml} / \mathrm{kg}$, ip). Encontraron que la droga por ambas vías fue ineficaz para generar efectos sobre la consolidación del paradigma auditivo de condicionamiento de miedo, dado que no se alteró la respuesta de inmovilidad en el grupo experimental que recibió la droga, comparado con el grupo control que fue inyectado con vehículo. Lo mismo fue reportado en ratones (Cain, Blouin, \& Barad, 2004; Lee, Berger, Stiedl, Spiess, \& Kim, 2001; Murchinson et al., 2004). Esto indicaría que existen resultados contradictorios en este proceso de condicionamiento clásico y que se necesitan más estudios para dilucidar el fenómeno (Lee et al., 2001).

Este paradigma también se puede llevar a cabo con la presencia de un estímulo condicionado contextual en lugar de un tono (Morris, Westbrook, \& Killcross, 2005); por ejemplo, en la fase de entrenamiento se presentan apareadas una luz y un choque eléctrico. Luego, en la fase de testeo, la mera presencia de la luz genera la respuesta de sobresalto y miedo. Se reportó que el propranolol $1 \mathrm{mg} / \mathrm{kg}$, administrado de modo subcutáneo (sc), inmediatamente posterior al entrenamiento en este paradigma, es eficaz para reducir la expresión de la respuesta de sobresalto condicionado en ratones,

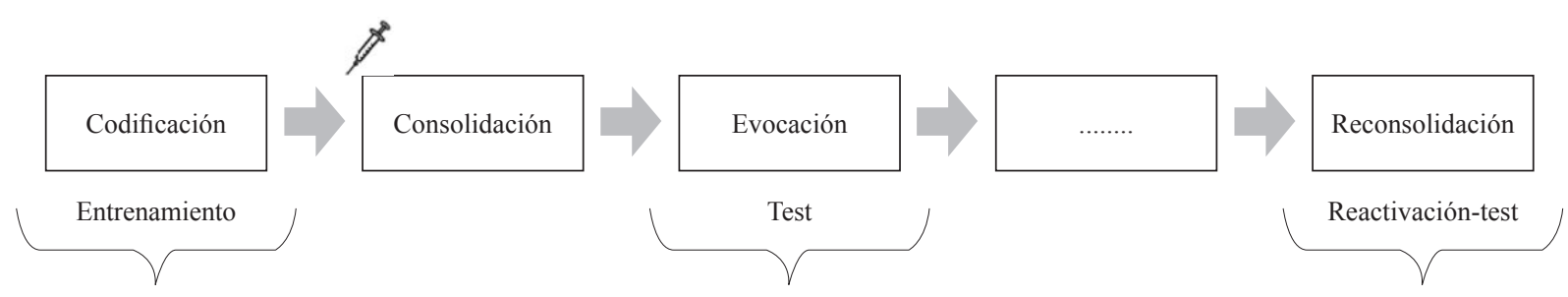

Figura 3. Representación del momento de aplicación de los tratamientos que permiten arrojar conclusiones acerca de la consolidación de la memoria. Implican una administración de la manipulación experimental posentrenamiento 
es decir que los sujetos no muestran la respuesta de miedo comparados con los animales que recibieron la administración de la sustancia vehículo (Ouyang \& Thomas, 2005; LaLumiere, Buen, \& McGaugh, 2003) sin tener efecto en ratas (Davis, Redmond, \& Baraban, 1979).

En ese mismo diseño de condicionamiento de miedo, Rodriguez-Romaguera, Sotres-Bavon, Mueller y Quirk (2009) estudiaron la resistencia del fenómeno por medio de ensayos de extinción. La extinción implica, luego de la fase de entrenamiento ya descrita, varios ensayos en las cajas donde se muestra el EC solo (e.g. tono o luz), sin el choque eléctrico (EI). De este modo, los sujetos tienen que generar el nuevo aprendizaje consistente en que, en este caso, la luz o el tono predice la no aparición del choque. Ambos aprendizajes, el del condicionamiento de miedo y el de los ensayos de extinción, entran en conflicto y, de esta manera, se puede evaluar cuál es más resistente. Es esperable que, si se produce una extinción de la respuesta de miedo condicionada, la conducta de sobresalto disminuya a lo largo de los ensayos de extinción. Los autores encontraron que inyectar propranolol (10 mg/kg, ip) de forma previa a los ensayos de extinción redujo la expresión de miedo ya que, comparado con los controles que recibieron del vehículo, en el primer ensayo de extinción se encontró una menor respuesta de congelamiento. Sin embargo, la droga no dañó la consolidación de la extinción porque a lo largo de los ensayos siguientes la conducta de sobresalto igualmente terminó disminuyendo. Esto se replica si se emplea tanto un proceso de extinción total, con todos los ensayos iguales sin EI, como de forma parcial, en el que la mitad de los ensayos son apareados tono-choque (Rodriguez-Romaguera et al., 2009).

Por otro lado, Cohen et al. (2011) exploraron los efectos del propranolol en un modelo animal de desorden de estrés postraumático. En el entrenamiento, este paradigma consiste en exponer a ratas por 10 minutos a una caja de arena de gato sucia con olor a ese predador natural para generar la experiencia aversiva. En comparación con el grupo control que es colocado en una caja limpia, en la fase de evaluación se mide la respuesta de miedo del animal en la caja de arena sin olor. Los autores inyectaron propranolol a los sujetos una hora después del entrenamiento (10 y $15 \mathrm{mg} / \mathrm{kg}$, sc). A los 30 días, los animales fueron evaluados en un laberinto en cruz elevado y en un paradigma de sobresalto auditivo para evaluar ansiedad. Luego, a las 24 horas, se presentó nuevamente la caja de arena limpia y se contabilizó el porcentaje de tiempo de la conducta de congelamiento para operacionalizar la respuesta de miedo en estos animales. No se encontraron efectos de la droga en ninguna de las fases del paradigma experimental (Cain et al., 2004; Cohen et al., 2011).

A su vez, el paradigma de laberinto acuático de Morris es una tarea de memoria espacial en la que en una arena circular con agua se coloca una plataforma sumergida y no visible. En la fase entrenamiento, los roedores nadan libremente explorando, y luego de encontrar la plataforma de forma azarosa deben emplear las claves contextuales externas para recordar su ubicación en los ensayos posteriores; luego de varios ensayos encuentran rápidamente la plataforma nadando lo menos posible para llegar a ella. En la fase de test, se retira la plataforma y se contabiliza la latencia en ir hacia la zona donde estaba ubicada, junto con el tiempo de permanencia en el área. Un desempeño exitoso implica la correcta localización de la plataforma con un menor tiempo de latencia y un mayor tiempo de permanencia en el área donde debería encontrarse la plataforma. Cahill, Pham y Setlow (2000) inyectaron a ratas con propranolol (2 mg/ $\mathrm{kg}, \mathrm{sc}$ ) inmediatamente después de 6 ensayos de entrenamiento. A las 24 horas fue la fase de test. Encontraron que la droga deterioró el aprendizaje dado que el grupo experimental mostró mayor tiempo en llegar al lugar donde estaba la plataforma, mientras que los animales controles resolvieron la tarea en un menor tiempo. Los mismos efectos fueron reportados con una dosis elevada de $45 \mathrm{mg}$ / 
kg, ip (Cohen \& Hamburg, 1975), aunque en este caso no pueden descartarse efectos inespecíficos, como la sedación (Pontecorvo, Clissold, White, \& Ferkany, 1991). Resultados similares fueron encontrados cuando la droga se administró por medio de infusiones, tanto en la región hipocampal CA1 (Ji, Zhang, \& Li, 2003) o en los núcleos basolaterales de la amígdala (Hatfield \& McGaugh, 1999).

Estos datos permiten pensar que el sistema NA se encuentra involucrado principalmente en la consolidación de la memoria espacial y contextual, más que en el procesamiento de experiencias aversivas. Sin embargo, sí se encontraron efectos del antagonista en el paradigma de evitación condicionada. Éste consiste en colocar a los roedores en una plataforma elevada y descubierta. Debido a la tendencia natural de los animales a evitar lugares elevados e iluminados, éstos suelen descender hacia el compartimiento inferior que se encuentra menos iluminado y sin altura. Cuando los sujetos bajan, reciben un choque eléctrico, lo que genera que en los posteriores ensayos eviten esa conducta natural y permanezcan mayor tiempo en la plataforma elevada. Está reportado que la administración de propranolol posentrenamiento puede generar deterioro en este aprendizaje, es decir que los sujetos experimentales tienden a bajar más rápidamente que los controles hacia el lugar donde habían recibido el choque, dando cuenta de un efecto amnésico de la droga (Decker, Gill, \& McGaugh, 1990; Sara, Datta, \& Sharma, 1991; Introini-Collison, Dalmaz, \& McGaugh, 1996; Izquierdo et al., 1992), ya sea inyectada de forma aguda o crónica (Nielson, Czech, \& Laubmeie, 1999) y en distintas dosis, como 2, 4, 8 y $12 \mathrm{mg} /$ $\mathrm{kg}$, ip (Nielson et al., 1999). Los efectos se vieron cuando el choque era de intensidad elevada y no cuando fue bajo (Gold, Vogt, \& Hall, 1986). En este mismo paradigma se demostró que el almacenamiento de información puede acentuarse, es decir generar una mejor memoria, si se infunde noradrenalina (agonista adrenérgico) posentrenamiento en la amígdala. Comportamentalmente, se observa que los sujetos tienden a permanecer mayor tiempo en la plataforma elevada en comparación con los sujetos controles, efecto que a su vez es bloqueado por la administración de propranolol (Liang, Juler, \& McGaugh, 1986; Liang, McGaugh, \& Yao, 1990).

Con base en esto, podría hipotetizarse que las diferencias reportadas en los aprendizajes aversivos es producto de distintos niveles de estrés generados por las particularidades de cada paradigma, lo que produce que el antagonista tenga o no efecto. Para evaluar la interacción del sistema NA en la consolidación y el nivel de estrés de la tarea, Schneider, Simson, Atapattu y Kirby (2001) probaron los efectos del propranolol $(10 \mathrm{mg} / \mathrm{kg}$, ip) en un paradigma de evitación pasiva seguido de un paradigma de natación forzada. De esta forma, en la fase de entrenamiento, las ratas fueron colocadas en un corredor con dos cámaras de diferente intensidad lumínica. Cuando los sujetos, por su tendencia natural de preferir los lugares oscuros comparados con los iluminados, cambiaban al sector más oscuro recibían un choque $(0,5 \mathrm{~mA}, 0,5 \mathrm{~s})$. Inmediatamente después fueron colocados por 15 minutos en un recipiente con agua tibia a modo de estresor donde debían permanecer flotando para respirar, o permanecían en la caja hogar en el caso del grupo control. Luego, recibieron la droga y a las 24 horas fueron testeados nuevamente en la caja de evitación pasiva, contabilizado la latencia en cruzar al compartimento asociado al choque. A mayor latencia en ingresar al compartimiento oscuro, puede inferirse un mayor aprendizaje. Encontraron que el propranolol, solo seguido a un estresor intenso, generó un daño en la retención, es decir que los animales pasaban más rápido al compartimento oscuro, sin encontrarse efectos de la droga en ausencia del nado forzado. Esto apoya la hipótesis planteada de que el nivel de estrés del paradigma experimental es determinante para encontrar un efecto del antagonista noradrenérgico.

Además, en este paradigma de evitación pasiva, si se administra adrenalina posentrenamiento se halla un aumento en la retención que puede ser 
bloqueado si a su vez se inyecta propranolol $(0,5$ $\mathrm{mg} / \mathrm{kg}$, ip) previo a la fase de entrenamiento (Gold $\&$ Buskirk, 1978) o si se aplica infusiones en la amígdala de la droga (Gallagher, Kapp, Musty, \& Driscoll, 1977; Lennartz, Hellems, Mook, \& Gold, 1996). También se puede producir un efecto amnésico en este diseño si se estimula la corteza frontal en ratas $(5 \mathrm{~mA} / 1 \mathrm{seg})$ a través de electrodos, lo cual puede revertirse con la administración de propranolol (0,5 mg/kg, ip; Sternberg \& Gold, 1985).

Por otra parte, un paradigma de reconocimiento del sabor es un diseño que permite evaluar el aprendizaje gustativo y la memoria por medio de dos ensayos en cajas de condicionamiento. Durante el entrenamiento (primer ensayo), se les presenta a las ratas acceso a una solución de sacarosa al 4\%, en la que adquieren la información del gusto y la consolidan. A las 24 horas se expone nuevamente a los animales a la solución de sacarosa y se evalúa su consumo. Por la tendencia natural de los animales a la fobia de lo desconocido o neofobia, se espera que la nueva presentación de la solución genere un mayor consumo comparado con el primer ensayo, dado que la solución dejó de ser novedosa. Ruetti, Justel, Mustaca y Boccia (2014) encontraron que la administración de propranolol (1 y $2 \mathrm{mg} / \mathrm{kg}$, ip) inmediatamente posterior al entrenamiento generó un deterioro en el reconocimiento, dado que las ratas que recibieron la droga consumieron significativamente menos la solución azucarada en el segundo ensayo, en comparación con el grupo control que recibió la inyección de vehículo. No se vieron efectos cuando el propranolol fue administrado 3 horas después del entrenamiento, lo que permite pensar que la droga no posee consecuencias cuando la experiencia de consumo de la solución ya fue consolidada adecuadamente (Ruetti et al., 2014).

También se reportó la acción de la droga en el ya descrito paradigma de reconocimiento al sabor. Se administró propranolol en la región central y basolateral de la amígdala luego de la presentación del sabor novedoso (Bahar, Samuel, Hazvi, \& Dudai, 2003). Se halló una disociación entre estas dos regiones, ya que la administración del antagonista deterioró el aprendizaje de la aversión gustativa dado que el grupo experimental persistió con la neofobia, sólo cuando se administró la droga en la primera región de la amígdala la cual se encuentra vinculada con la producción de las respuestas emocionales. Esto permite concluir que los receptores noradrénergicos de ese área cerebral se encuentran involucrados en la consolidación de este paradigma.

Contrariamente a la neofobia que se produce con los sabores, los roedores prefieren explorar los objetos novedosos comparados con los conocidos. Un paradigma experimental para evaluar esto es el diseño de exploración de objetos novedosos que también permite estudiar diferentes procesos de memoria. Cohen et al. (2011) indagaron el efecto del propranolol en la consolidación de este aprendizaje. Puntualmente, consiste en exponer a las ratas a una arena con dos objetos similares entre sí; éste sería el primer ensayo de 10 minutos en el que exploran el espacio y los objetos. Luego de un intervalo variable los animales son reexpuestos a la arena con un objeto de los ya conocidos y uno nuevo que es diferente en tamaño, forma, color y textura. Como se mencionó, tienden naturalmente a explorar el objeto novedoso sobre el conocido. Los autores administraron propranolol o vehículo luego del entrenamiento y encontraron que el antagonista adrenérgico (10 y $20 \mathrm{mg} / \mathrm{kg}$, sc) redujo significativamente la exploración del objeto novedoso, en comparación con el grupo control que estuvo más tiempo explorando el elemento novel.

Del mismo modo, Zhang, He, Chen, Wang y Ma (2008) estudiaron el rol del antagonista $\beta$-adrenérgico en la consolidación de la memoria en un laberinto en Y, dispositivo para evaluar memoria espacial consistente en 3 brazos o corredores, en este caso idénticos entre sí. En la fase de entrenamiento, los sujetos exploraron el aparato por 10 minutos con uno de los 3 brazos bloqueados. Después los ratones recibieron una inyección de propranolol (2, 10 o $20 \mathrm{mg} / \mathrm{kg}$, ip) y a las 2 horas de 
intervalo, en la fase de test, podían recorrer todos los sectores libremente. Con base en la tendencia natural de los roedores a explorar lo novedoso en comparación con lo ya conocido, es esperable que permanezcan más tiempo en el brazo que estuvo tapado en la fase de entrenamiento. Ninguna de las dosis deterioró este efecto. Esto permite inferir que en dicho paradigma de claves espaciales el propranolol no tiene efectos sobre la consolidación de la memoria. El mismo resultado fue hallado por Sun et al. (2011).

A su vez, Justel et al. (2014) evaluaron los efectos del propranolol en la consolidación de la novedad como modulador de la frustración. Como se describió en el apartado anterior, el diseño experimental de los autores consiste en utilizar un campo abierto (CA) como novedad, aplicado tanto en el primer ensayo de contacto con la solución devaluada en un paradigma de CSNc (E1), como en el segundo contacto con ésta (E2). En el E1, la inyección de propranolol (4,5 mg/kg, ip) administrada inmediatamente luego del CA no generó efectos, es decir que tanto el grupo que recibió el vehículo como la droga posterior a la novedad mostraron una igual frustración. Por el contrario, en el E2, donde el efecto de la novedad consiste en generar una acentuación de la frustración, la aplicación farmacológica posterior al CA generó un bloqueo de dicho efecto amnésico dado que el grupo que recibió la droga no mostró una mayor frustración, comparado con el que recibió el vehículo. Esto permite concluir que el sistema NA y el efecto del propranolol están presente en la consolidación de la novedad en el E2 (Justel et al., 2014).
Todos estos resultados permiten mostrar el rol del sistema NA en la consolidación de diversos paradigmas. Estos datos son consistentes con estudios en los que la metodología incluye la producción de lesiones en áreas de interés o el uso de ratones knock-out, en los cuales se presenta una depleción del sistema NA simulando el efecto del bloqueante $\beta$-adrenérgico. La participación noradrenérgica puede observarse tanto en paradigmas de memoria espacial, reconocimiento de sabores, exploración de la novedad, así como aprendizajes aversivos y apetitivos (Gallagher et al., 1977; Hatfield \& McGaugh, 1999).

\section{Propranolol y evocación de la memoria}

Para evaluar la evocación de la memoria es pertinente investigar el efecto de los tratamientos experimentales aplicados de manera previa al test cuando el entrenamiento ya fue codificado y el aprendizaje se almacenó correctamente (ver figura 4). En este proceso de evaluación de la memoria se encuentra involucrado el sistema NA (McGaugh, 2000), por lo cual es esperable que la acción de un antagonista genere efectos en esta instancia.

Stuchlik, Petrasek y Vales (2009) expusieron a los animales al paradigma de evitación activa de lugar, el cual es un diseño que permite evaluar la memoria espacial. El entrenamiento consiste en ensayos de 20 minutos en una plataforma circular giratoria donde se coloca a las ratas. Los sujetos deben caminar en la dirección contraria al sentido de giro de la arena para evitar un choque eléctrico que se les administra al pasar por un sector

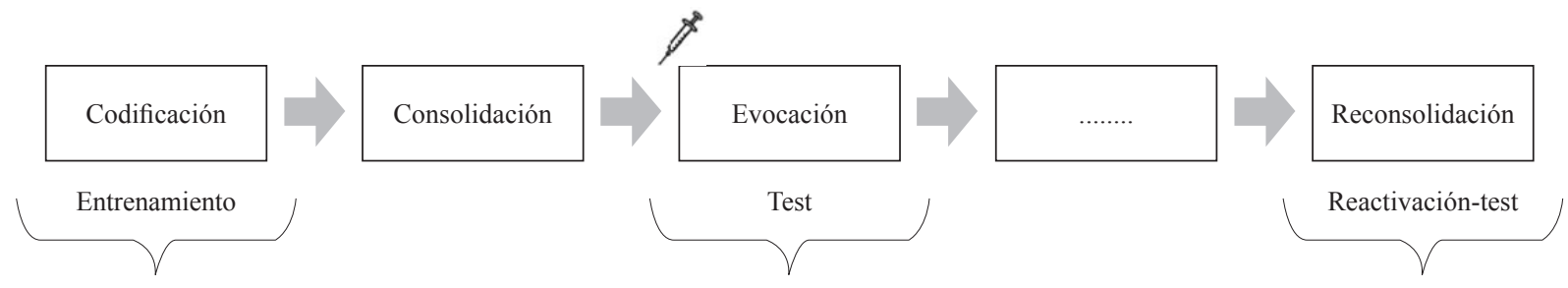

Figura 4. Representación del momento de aplicación de los tratamientos que permiten arrojar conclusiones acerca de la evocación de la memoria. Implican una administración de la manipulación experimental pretest 
específico. Para ello, deben orientarse con las claves exteriores e inhibir la información de las claves de la superficie de la arena, como las defecaciones, dado que la plataforma cambia de lugar. En la fase de test se los coloca en la misma arena sin la aplicación del choque, y se evalúa el recorrido de los sujetos, la distancia total recorrida, la cantidad de errores al ingresar al sector de choque y el tiempo de latencia del primer error como indicadores del reconocimiento espacial. Es esperable, en un buen desempeño, que los sujetos se mantengan activos para evitar el ingreso al sector en donde se provee el choque. Los autores mostraron que el propranolol (25 $\mathrm{mg} / \mathrm{kg}$, ip) administrado previamente al test en esta tarea generó un deterioro en el desempeño ya que los sujetos tuvieron más ingresos al sector donde recibieron el estímulo aversivo, en comparación con los controles que fueron inyectados con la sustancia vehículo. Además, reportaron que dosis elevadas (30 mg/kg, ip) generaron un descenso en la actividad general y dosis bajas no tuvieron efecto $(5$ y $20 \mathrm{mg} / \mathrm{kg}$, ip) en el número de entradas al sector del estímulo eléctrico (Stuchlik et al., 2009).

Por otro lado, Roozendaal, de Quervain, Schelling y McGaugh (2004) evaluaron el efecto del propranolol en la evocación del paradigma ya descrito de evitación condicionada en ratas. Para ello, 48 horas después del entrenamiento, 30 minutos antes del test, administraron el fármaco $(2 \mathrm{mg} / \mathrm{kg}$, ip). Encontraron que la droga no generó deterioro por si sola en el desempeño de esta prueba, es decir que los sujetos actuaron como los controles permaneciendo en la plataforma elevada evitando recibir el choque eléctrico. Sin embargo, la administración de corticosterona antes del test produjo un deterioro en el aprendizaje, generando una menor latencia a bajar. Este efecto deteriorador puede ser bloqueado si se administra propranolol ( $2 \mathrm{mg} / \mathrm{kg}$, ip) junto con la primera droga (Roozendaal et al., 2004). Esto permite pensar en la interacción del sistema noradrenérgico con la activación glucocorticoide y los niveles de estrés en esta fase.
También se puede producir una activación del sistema glucocorticoide en roedores por medio de la aplicación de un estresor, como la exposición al olor de un predador. Si esta activación del sistema adrenérgico se aplica previo a una fase de testeo en el laberinto acuático de Morris explicado previamente, se genera un deterioro de la memoria que se evidencia por una mayor latencia en encontrar la zona de la plataforma sumergida (Campbell et al., 2008). El propranolol (5 y $10 \mathrm{mg} / \mathrm{kg}$, ip), administrado después a ese estresor, no bloqueó la amnesia inducida por el olor del predador (Campbell et al., 2008).

Otro paradigma experimental con componentes espaciales es el laberinto complejo motivado por comida. Éste consiste en colocar a los roedores en un dispositivo con diversos caminos, uno de los cuales posee comida, y se les permite que lo exploren libremente durante el ensayo. Dado que los sujetos se encuentran privados de comida, la localización azarosa de ésta resulta como un refuerzo. En la fase de test, los sujetos deben recordar la ubicación del alimento y es esperable que vayan hacia el sector donde se encuentra en el menor tiempo posible. Está reportado que la estimulación del locus coeruleus (LC) a través de electrodos previamente al test (Devauge \& Sara, 1991) genera un efecto amnésico ya que los sujetos muestran un deterioro en su desempeño para localizar la comida. Devauge y Sara (1991) encontraron que si se administraba propranolol $(0,5 \mathrm{mg} / \mathrm{kg}$, ip) se prevenía el efecto amnésico generado por dicha estimulación, es decir que el grupo experimental tuvo una menor latencia para encontrar el alimento, comparado con el grupo que recibió la estimulación del LC seguida de la administración del vehículo (Devauge \& Sara, 1991).

Por otro lado, Heron, Gould y Bickford (1995) desarrollaron un paradigma de corredor recto que permite evaluar el aprendizaje motor y reconocimiento. En éste los roedores exploran varios sectores equidistantes entre sí, donde hay recipientes 
con agua en los extremos como recompensa. En el entrenamiento, las ratas con 12 horas de privación de agua aprendieron a recorrerlo en busca del mencionado refuerzo. En la fase de testeo los sectores eran irregulares, por lo cual resultaban novedosos para los sujetos. Es esperable que los sujetos a lo largo de los ensayos disminuyan la latencia de recorrido en el corredor para encontrar el agua. Los autores hallaron que el propranolol (10 mg/kg, ip) aplicado 30 minutos antes del test generó un deterioro del desempeño de los sujetos, dado que, si bien disminuía el tiempo de resolución de la tarea, los tiempos fueron significantemente mayores que para los controles (Heron et al., 1995).

Con el objetivo de determinar los parámetros de la droga sobre el laberinto en Y, Sun et al. (2011) inyectaron a ratones propranolol (2, 10 y $20 \mathrm{mg} /$ $\mathrm{kg}$, ip) inmediatamente antes del testeo. Como se explicó en el apartado anterior, este paradigma consiste en presentar en la fase de testeo un brazo desconocido para los sujetos que es esperable que recorran en mayor medida. Los autores encontraron que ninguna dosis generó efectos amnésicos, es decir que los sujetos exploraron el sector novedoso en mayor medida que el conocido al igual que los controles, a diferencia de cuando se aplicó el tratamiento en la fase de consolidación.

Por lo expuesto, puede pensarse que, si bien el sistema NA se encuentra involucrado en el proceso de evocación de la memoria (McGaugh, 2000), el efecto de este antagonista depende del diseño empleado. El sistema se encuentra involucrado en la evocación de la evitación activa de lugar y en la evitación condicionada, paradigmas que implican estímulos aversivos. A su vez, se reportaron efectos del propranolol sobre la evocación de aprendizajes espaciales y la interacción de esta droga con los efectos de otros fármacos que afectan al sistema adrenérgico en esta fase de evaluación de la memoria.

\section{Propranolol y reconsolidación de la memoria}

El estudio experimental del proceso de reconsolidación implica labilizar memorias ya consolidadas mediante la inclusión de una sesión de reactivación. Para estudiar el efecto del propranolol en el proceso de reconsolidación es necesario administrar la droga durante la labilización de la memoria, es decir en el ensayo de reactivación (ver figura 5).

Por ejemplo, el paradigma de condicionamiento de miedo en roedores implica una fase de entrenamiento en la que se presenta un choque eléctrico (estimulo incondicionado, EI), que genera una respuesta de sobresalto, junto con la presencia de un tono (estímulo condicionado, EC). En la fase de test se presenta el EC solo, que produce por sí mismo la respuesta condicionada de sobresalto. En la reactivación de esta memoria se vuelve a presentar sólo el EC y luego se inicia una nueva fase de test para evaluar así la reconsolidación del aprendizaje (Robinson et al., 2011). También, se puede implementar una fase de restablecimiento en la que se

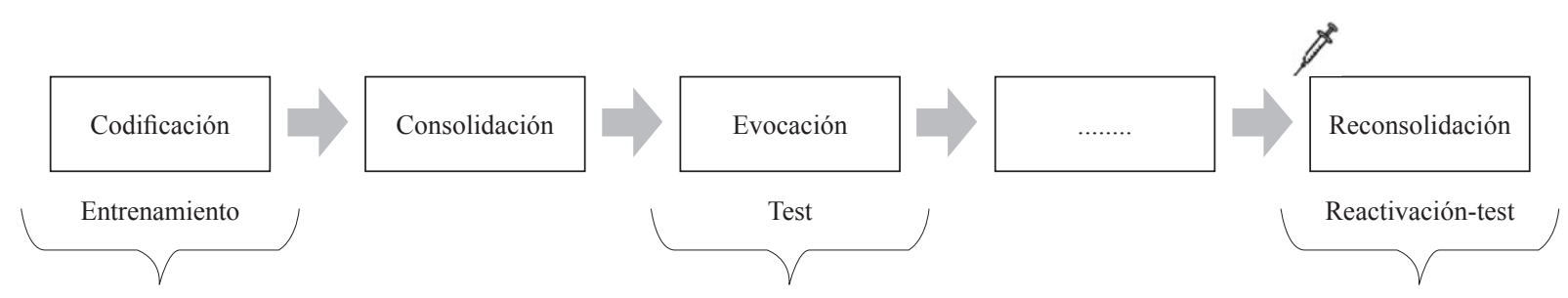

Figura 5. Representación del momento de aplicación de los tratamientos que permiten arrojar conclusiones acerca de la reconsolidación de la memoria. Implican una administración de la manipulación experimental durante la labilización de la memoria, es decir en el ensayo de reactivación 
presenta nuevamente el EI; por ejemplo, en este caso representaría un nuevo ensayo tono-shock.

En este paradigma de condicionamiento de miedo en ratas, Debiec y Ledoux (2004), luego de la etapa de entrenamiento, realizaron una fase de restablecimiento en la que los sujetos fueron expuestos nuevamente al choque que había estado apareado al tono e inmediatamente después recibieron inyecciones sistémicas de propranolol $(1 \mathrm{mg} / \mathrm{kg}$, ip). Luego de 24 horas, los roedores tuvieron una nueva fase de testeo o reactivación, en la cual recibieron sólo el tono y se registró el porcentaje de congelamiento o inmovilización. Los sujetos inyectados con la droga mostraron una menor respuesta de congelamiento comparado con el grupo que recibió vehículo. Los mismos datos se replicaron cuando la droga se administró por medio de infusiones intraamigdalinas $(2,5 \mu \mathrm{g})$ $\mu 1)$. Esto permite inferir que por ambos métodos el propranolol fue eficaz para bloquear el proceso de reconsolidación cuando estuvo seguido de una fase de restablecimiento (nueva presentación de EI). Por ende, puede pensarse que la trasmisión NA, que no es determinante para la consolidación de esta memoria aversiva como se reportó, juega un papel fundamental en este proceso. Esta información apoya la hipótesis que sostiene que la consolidación y la reconsolidación son procesos de la memoria con características particulares.

Por otro lado, Przybyslawski, Roullet y Sara (1999) evaluaron el efecto del propranolol administrado después a la fase de reactivación en un laberinto elevado con ratas. Este paradigma consistió en colocar a los sujetos en el aparato diseñado con ocho brazos radiales en los cuales tres de ellos, durante los tres ensayos diarios de entrenamiento, se encontraban con comida. Luego del entrenamiento se aplicó una sesión de test, en la que los sujetos debían emplear las claves contextuales proximales y distales para ubicar los brazos reforzados con la comida. A las 24 horas se aplicó una sesión de reactivación que consistió en un solo recorrido en el laberinto, y después los roedores fueron inyectados con propranolol $(10 \mathrm{mg} / \mathrm{ml}$, ip) a los 5 minutos, 2 o 5 horas. Luego, se realizó una nueva fase de testeo. Encontraron que los sujetos inyectados con la droga a las 2 horas tuvieron un peor desempeño, permitiendo inferir el efecto amnésico tiempo-dependiente de la droga en la reconsolidación de este paradigma.

Del mismo modo, Przybyslawski et al. (1999) evaluaron el efecto del propranolol inyectado luego de la fase de reactivación en un paradigma de evitación pasiva. En éste se aplica un choque eléctrico cuando los roedores se trasladan, según una preferencia innata, de una cámara iluminada a una más oscura. En este diseño la reactivación consistió en colocar a los sujetos nuevamente en la caja. Inmediatamente después de ese nuevo ensayo se administró la droga (10 mg/kg, ip). La fase de test se realizó a las 24 horas sin el choque y se registró la latencia de los sujetos a ingresar al compartimento oscuro (una mayor latencia muestra un mayor aprendizaje). Se encontró que el grupo experimental tuvo una menor latencia de ingreso al sector oscuro, lo cual indica un deterioro en el aprendizaje comparado con el grupo control que permaneció en el sector iluminado. Estos datos dan cuenta de la participación del antagonista adrenérgico en la fase de reconsolidación de la memoria en este paradigma aversivo.

A su vez, Robinson y Franklin $(2007,2010)$ evaluaron los efectos de la droga en el paradigma de preferencia de lugar con morfina, que es un modelo animal para estudiar el efecto reforzante de dicha droga y el recuerdo de claves contextuales. El entrenamiento consistió en sesiones diarias en las que los roedores fueron inyectados con morfina ( $5 \mathrm{mg} / \mathrm{kg}$, ip) e introducidos a la cámara A del aparato. En la sesión siguiente se los inyectó con vehículo y se los colocó en la cámara $B$, que posee características contextuales diferentes. De este modo, los sujetos asocian las consecuencias placenteras de la droga con el primer contexto. En la fase de testeo los sujetos no recibieron el narcótico y pudieron explorar libremente ambas cámaras. 
En esta última es esperable que permanezcan más tiempo en el sector que estuvo asociado a la morfina. Luego de ocho sesiones de entrenamiento, los autores realizaron la sesión de reactivación al día siguiente y a las 48 horas. Ésta consistió en una sesión de 30 minutos de libre acceso a ambas cámaras e inmediatamente después fueron inyectados con propranolol (10 o $40 \mathrm{mg} / \mathrm{kg}$, sc) o salina. Robinson y Franklin $(2007,2010)$ reportaron que la droga deterioró la reconsolidación dado que los sujetos no mostraron la preferencia esperable, cuando la droga se administró luego de la reactivación hecha a las 24 horas sin tener efectos a las 48 horas. También este fenómeno fue más robusto con la dosis más elevada. Esto permite concluir que es necesario el elemento novedoso en el ensayo de labilización de la memoria, ya que tras una segunda sesión de reactivación el propranolol no tuvo efectos.

Por ende, puede concluirse que la droga tiene efectos amnésicos sobre la reconsolidación de la memoria, aunque es necesario el desarrollo de mayor cantidad de investigaciones al respecto. Sobre todo, este tipo de estudios adquieren gran relevancia dado que permiten brindar información acerca de posibles aplicaciones terapéuticas, siendo una herramienta disponible para intervenir en trastornos psicológicos, como el desorden por estrés postraumático en el que la dinámica del tratamiento se basa en la reactivación de las vivencias traumáticas para cambiar su valencia afectiva y el impacto emocional (Pitman et al., 2002).

\section{Conclusiones}

Este trabajo indagó los efectos del propranolol en la memoria y el aprendizaje en modelos animales. En relación con la codificación de la memoria, se ha reportado que esta droga está involucrada en la codificación del laberinto en Y (Zhang et al., 2008), así como en la codificación de la novedad como modulador de la frustración en el paradigma consumatorio de CSN (Justel et al., 2014) y en el aprendizaje aversivo al sabor (Bahar et al.,
2003; Justel \& Ruetti, 2012; Justel et al., 2014). En relación con la consolidación de la memoria, el propranolol genera efectos amnésicos en el paradigma de laberinto acuático de Morris (Cahill et al., 2000); en la evitación condicionada (Decker et al., 1990; Introini-Collison et al., 1996; Izquierdo et al., 1992; Sara et al., 1991); en el paradigma de reconocimiento al sabor (Ruetti et al., 2014); en el paradigma de evitación pasiva (Gold \& Buskirk, 1978; Gallagher et al., 1977; Lennartz et al., 1996; Sternberg \& Gold, 1985); en el paradigma de reconocimiento de objetos (Cohen et al., 2011) y el la consolidación de la novedad como modulador de la frustración (Justel et al., 2014). No se reportan efectos sobre la consolidación del paradigma de condicionamiento de miedo (Debiec \& Ledoux, 2004) en el paradigma de laberinto en $Y$ (Zhang et al., 2008) y ante un paradigma animal de desorden por estrés postraumático (Cohen et al., 2011).

Los resultados sobre la evocación de la memoria incluyen el efecto amnésico del fármaco en una tarea de evitación activa de lugar (Stuchlik et al., 2009) y en el paradigma de corredor recto (Heron et al., 1995), sin alterar el paradigma de inhibición pasiva (Roozendaal et al., 2004), el laberinto acuático de Morris (Campbell et al., 2008), el laberinto en Y (Zhang et al., 2008) y un laberinto complejo motivado por comida (Devauge \& Sara, 1991). Con respecto a la reconsolidación de la memoria, la droga generó efectos amnésicos en el paradigma de condicionamiento de miedo (Debiec \& Ledoux, 2004), en la evitación pasiva, en un laberinto elevado (Przybyslawski et al., 1999) y en el paradigma de condicionamiento de preferencia de lugar (Robinson \& Franklin, 2007, 2010).

Estos datos permiten mostrar la relevancia del sistema NA para la memoria, la exploración de la novedad y el aprendizaje en general. Esto permite pensar en el valor que poseen dichos neurotransmisores para la adaptabilidad y el desarrollo de la vida diaria de los sujetos. Además, pueden evidenciarse diferencias según los procesos de memoria, viéndose hallazgos particulares de un mismo pa- 
radigma dependiendo de la fase de su aplicación (e.g. se reportan efectos del propranolol sobre la codificación del laberinto en $Y$, sin alterar su consolidación o evocación; Zhang et al., 2008).

Por otro lado, se pueden observar resultados diferentes del accionar de la droga en una misma fase de la memoria. En primer lugar, esto puede atribuirse al diseño experimental empleado y a las características intrínsecas de las tareas evaluadas. Puede reportarse un mayor efecto del fármaco para deteriorar el desempeño de tareas con claves espaciales y contextuales, como el laberinto en Y, comparado con tareas aversivas, como el recuerdo de un choque eléctrico. Además, estas tareas implican distintos niveles de estrés, lo que puede considerarse un factor influyente para generar el efecto (Schneider et al., 2011). Lo mismo ocurre cuando se emplean distintos niveles de intensidad de los estímulos aversivos (Gold et al., 1986). También puede pensarse que hay una distinción entre aquellos paradigmas que implican una conducta operante de aquellos que no, prevaleciendo los efectos de la droga en los aprendizaje del primer tipo, como en el paradigma de laberinto acuático (Cahill et al., 2000) y en el paradigma de evitación condicionada (Decker et al., 1990; Introini-Collison et al., 1996; Izquierdo et al., 1992; Sara et al., 1991; Stuchlik et al., 2009).

Por otro lado, es importante señalar la posible existencia de un efecto dosis-dependiente. Se han reportados efectos distintos según las concentraciones del fármaco (Angrini, Leslie, \& Shephard, 1997), incluyéndose efectos secundarios no deseados en las concentraciones más altas (Pontecorvo et al., 1991). Además, dado que todos los tratamientos fueron aplicados 30 minutos antes o inmediatamente después según el proceso de memoria que se buscó intervenir, cabe destacar que la ineficacia de algunas concentraciones no puede atribuirse al tiempo de administración ya que se respetó la farmacocinética de la droga.

A su vez, es necesario indagar la influencia de la vía de administración seleccionada, ya sea ip, sc o por infusiones, dado que estas muestran resultados diferentes en algunos paradigmas y las mismas tendencias en otros (Berlau \& McGaugh, 2006; Mueller et al., 2008). Del mismo modo, esto no puede atribuirse exclusivamente a un fenómeno dependiente de la especie animal investigada, dado que, en general, se replican los mismos resultados para ratas y ratones, por ejemplo (Cain et al., 2004; Lee et al., 2001; Murchinson et al., 2004). Por otra parte, con base en los resultados publicados de tareas en las que se puede diferenciar el grado de ansiedad y la actividad locomotora del desempeño en el paradigma, no pueden atribuirse los efectos amnésicos de la droga solamente a su rol como ansiolítico (Stuchlik et al., 2009).

A su vez, debido a que el procesamiento de los estímulos puede verse afectado por distintos constructos psicológicos y efectos fisiológicos inespecíficos generados por los paradigmas experimentales, resulta pertinente preguntarse si los resultados reportados tienen interacción con las consecuencias de la administración de la droga sobre ansiedad y motivación, por ejemplo. Para ello, es necesario indagar el efecto del propranolol sobre éstos. Está reportado que la droga posee efectos ansiolíticos (Angrini et al., 1997, Cohen et al., 2011; Lucki, Ward, \& Frazer, 1989; Prut \& Belzung, 2003) y que afecta el sistema nervioso central de los sujetos (Rex, Voigt, Voits, \& Fink, 1998). Sin embargo, no genera efectos sobre la actividad locomotora ni altera la motivación (Rodriguez-Romaguera et al., 2009). Si bien es posible disociar los efectos principales de la droga sobre la memoria, cabe destacar que no se puede eliminar la posibilidad de que estas variables estén presentes; para ello es fundamental un adecuado diseño experimental.

Por otro lado, la administración del propranolol puede plantearse como una herramienta plausible de emplear en intervenciones en humanos. Por ejemplo, se ha demostrado que esta droga daña la consolidación de memorias declarativas (Cahill, Prins, Weber, \& McGaugh, 1994; McGaugh, 2000). También deteriora memorias aversivas, después de 
una fase de reactivación (Debiec \& Ledoux, 2004), siendo una alternativa útil para tratar desórdenes por estrés postraumático. Incluso se probó que la administración de propranolol, a $40 \mathrm{mg}$ de dosis oral, fue efectiva para reducir síntomas si es administrada poco después de un evento traumático agudo, evaluando los síntomas un mes (Pitman et al., 2002) o dos meses después (Vaiva et al., 2003) en sujetos humanos.

Así mismo, el propranolol ha demostrado ser eficaz en la eliminación de la respuesta física que impide un adecuado rendimiento causado por el pánico escénico (Brantigan, C., Brantigan, T., \& Joseph, 1982). Además, mejora el rendimiento en los estudiantes propensos a la disfunción cognitiva producto de la ansiedad (Alexander, Hillier, Smith, Tivarus, \& Beversdorf, 2007; Faigel, 1991) y genera una reducción de la activación emocional al regresar al contexto condicionado (Grillon, Cordova, Morgan, Charney, \& Davis, 2004).

Sin embargo, cabe destacar que no se puede pensar más que como una posible herramienta $y$, por ende, es necesario desarrollar más investigaciones que vinculen la ciencia básica con la aplicada. Para ello, el desarrollo de paradigmas animales es una alternativa eficaz para el avance del conocimiento.

\section{Referencias}

Alexander, J. K., Hillier, A., Smith, R. M., Tivarus, M. E., \& Beversdorf, D. Q. (2007). Beta-adrenergic modulation of cognitive flexibility during stress. Journal Cognitive Neuroscience, 19, 468-478. doi: 10.1162/jocn.2007.19.3.468

Angrini, M., Leslie, J. C., \& Shephard A. (1997). Effects of propranolol, buspirone, pCPA, reserpine, and chlordiazepoxide on open-field behavior. Pharmacology Biochemistry and Behavior, 59(2), 387-397. doi: 10.1016/S00913057(97)00457-7

Aston, J. G, Chiang, C., \& Alexinsky, T (1991). Discharge of noradrenergic locus coeruleus neurons in behaving rats and monkeys suggests a role in vigilance. Progress in Brain Research, 88, 501-520.

Berlau, D. J. \& McGaugh, J. L. (2006) Enhancement of extinction memory consolidation: The role of the noradrenergic and GABAergic systems within the basolateral amygdale. Neurobiology of Learning and Memory, 86, 123-132. doi: 10.1016/j.nlm.2005.12.008

Berman, D., Hazvi, S., Neduva, V., \& Dudai, Y. (2000). The role of identified neurotransmitter systems in the response of insular cortex to unfamiliar taste: activation of ERK1-2 and formation of a memory trace. The Journal of Neuroscience, 20(18), $7017-7$ 023. doi: 02706474/00/207017

Bahar, A., Samuel, A., Hazvi, S., \& Dudai, Y. (2003). The amygdale circuit that acquires taste aversion memory differs from the circuit that extinguishes it. European Journal of Neuroscience, 17, 1 527-1 530. doi: 10.1046/j.14609568.2003.02551.x

Brantigan, C. O., Brantigan, T. A., \& Joseph, N. (1982). Effect of beta blockade and beta stimulation on stage fright. The American Journal of Medicine, 72(1), 88-94. doi: 10.1016/00029343(82)90592-7

Cahill, L., Pham, C. A., \& Setlow, B. (2000). Impaired memory consolidation in rats produced with b-adrenergic blockade. Neurobiology of Learning and Memory, 74, 259-266. doi: 10.1006/ nlme.1999.3950

Cahill, L., Prins, B., Weber, M., \& McGaugh, J. L. (1994). Betaadrenergic activation and memory for emotional events. Nature, 371, 702-704.

Cain C. K., Blouin A. M., \& Barad. M. (2004). Adrenergic transmission facilitates extinction of conditional fear in mice. Learning \& Memory, 11, 179-187. doi: 10.1101/1m.71504

Campbell, A.M., Park R.C., Zoladz, P. R., Muñoz, C., Fleshner, M., \& Diamond, D. M (2008). Pre-training administration of tianeptine, but not propranolol, protects hippocampus-dependent 
memory from being impaired by predator stress. European Neuropsychopharmacology, 18, 8798. doi: 10.1016/j.euroneuro.2007.04.004

Cassel, J. C. (2010). Experimental studies on the role(s) of serotonin in learning and memory functions. Handbook of Behavioral Neuroscience - Handbook of the Behavioral Neurobiology of Serotonin, 21, 429-447. doi: 10.1016/S15697339(10)70094-1

Cohen, H., Kaplan, Z., Koresh, O., Matar, M.A., Geba, A. B., \& Zohar, J. (2011). Early post-stressor intervention with propranolol is ineffective in preventing posttraumatic stress responses in an animal model for PTSD. European Neuropsychopharmacology, 21, 230-240. doi: 10.1016/j. euroneuro.2010.11.011

Cohen, R. \& Hamburg, M. (1975). Evidence for adrenergic neurons in a memory access pathway. Pharmacology Biochemistry and Behavior, 3, 519-523. doi: 10.1016/0091-3057(75)90066-0

Davis, M., Redmond D. E., \& Baraban J. M. (1979). Noradrenergic agonists and antagonists: Effects on conditioned fear as measured by the potentiated startle paradigm. Psychopharmacology, 65, 111-118. doi: 10.1007/BF00433036

Debiec, J. \& Ledoux, J. E. (2004). Disruption of reconsolidation but not consolidation of auditory fear conditioning by noradrenergic in the amygdala. Neuroscience, 129, 267-272. doi: 10.1016/j.neuroscience.2004.08.018

Decker, M. D., Gill, T. M., \& McGaugh, J. L. (1990). Concurrent muscarinic and $\beta$-adrenergic blockade in rats impairs place-learning in a water maze and retention of inhibitory avoidance. Brain Research, 513, 81-85. doi: 10.1016/00068993(90)91091-T

Devauge, V. \& Sara, S. J. (1991). Memory retrieval enhancement by locus coeruleus stimulation: evidence for mediation by $\beta$-receptors. Behavioural Brain Research, 43, 93-97.

Faigel, H. C. (1991). The effect of beta blockade on stress-induced cognitive dysfunction in ado- lescents. Clinical Pediatrics, 30, 441-445. doi: 10.1177/000992289103000706

Fernández Teruel, A. (2008). Psicofarmacología de la conducta: de los psicofármacos a las terapias psicológicas. Barcelona: Servei de Publicaciones.

Ferry, B., Roozendaal, B., \& McGaugh, J. L. (1999). Role of norepinephrine in mediating stress hormone regulation of long-term memory storage: a critical involvement of the amygdala. Biological Psychiatry, 46, 1 140-1 152. doi: 10.1016/ S0006-3223(99)00157-2

Gallagher, M., Kapp B. S., Musty, R. E., \& Drisco11, P. A. (1977). Memory formation: evidence for a specific neurochemical system in the amygdala. Science, 198, 423-425. doi: 10.1126/ science. 20664

Giacovich, S. \& Enero, M. A. (1984). Decreased brain serotonergic activity after acute propranolol. European Journal of Pharmacology, 100, 123-125. doi: 10.1016/0014-2999(84)90325-X

Gibbs, M. E. \& Summers, R. J. (2002). Role of adrenoceptor subtypes in memory consolidation. Progress in Neurobiology, 67, 345-391. doi: 10.1016/S0301-0082(02)00023-0

Gold, P. \& Buskirk R. V. (1978). Effects of $\alpha$ and $\beta$ Adrenergic receptor antagonists on post-trial epinephrine modulation of memory: Relationship to post-training brain norepinephrine concentrations. Behavioral Biology, 24, 168-184. doi: 10.1016/S0091-6773(78)93045-6

Gold, P. E., Vogt, J., \& Hall, J. (1986). Glucose effects on memory: Behavioral and pharmacological characteristics. Behavioral and Neural Biology, 46, 145-155. doi: 10.1016/S01631047(86)90626-6

Grillon, C., Cordova, J., Morgan, C. A., Charney, D. S., \& Davis, M. (2004). Effects of the beta-blocker propranolol on cued and contextual fear conditioning in humans. Psychopharmacology, 175, 342-352. doi: 10.1007/s00213-004-1819-5

Hatfield, T. \& McGaugh, J. L. (1999). Norepinephrine infused into the basolateral amygdala posttrai- 
ning enhances retention in a spatial water maze task. Neurobiology of Learning and Memory, 71, 232-239. doi: 10.1006/nlme.1998.3875

Heron, C., Gould, T. J., \& Bickford, P. (1995). Acquisition of a runway motor learning task is impaired by a beta adrenergic antagonist in F344 rats. Behavioural Brain Research, 78, 235-241. doi: 10.1016/0166-4328(95)00252-9

Hunziker, L. \& Pérez-Acosta, A. (2001). Modelos animales en psicopatología: ¿una contribución o una ilusión? Avances en Psicología Clínica Latinoamericana, 19, 37-50.

Introini-Collison, I. B., Dalmaz, C., \& McGaugh, J. L. (1996). Amygdala beta-noradrenergic influences on memory storage involve cholinergic activation. Neurobiology of Learning and Memory, 65, 57-64. doi: doi:10.1006/nlme.1996.0006

Izquierdo, I., Da Cunha, C., Rosat, R., Jerusalinsky, D., Ferreira, M. B., \& Medina, J. H. (1992). Neurotransmitter receptors involved in posttraining memory processing by the amygdala, medial septum, and hippocampus of the rat. Behavioral and Neural Biology, 58, 16-26. doi: 10.1016/0163-1047(92)90847-W

Ji, J. Z., Zhang, X. H., \& Li, B. M. (2003). Deficient spatial memory induced by blockade of beta-adrenoceptors in the hippocampal CA1 region. Behavioral Neuroscience, 117, 1 378-1 384. doi: 10.1037/0735-7044.117.6.1378

Justel, N. \& Psyrdellis, M. (2014). Novedad y modulación de la memoria: mecanismos neurobiológicos implicados. Interdisciplinaria, 31(2), 1-8. Justel, N., Psyrdellis, M., Pautassi, R., \& Mustaca, A. (2014). Propranolol reverses open field effects on frustration. Neurobiology of Learning and Memory, 116, 105-111. doi: 10.1016/j. nlm.2014.09.00

Justel, N. \& Ruetti, E. (2012). La memoria del sabor. Revista Argentina de Ciencias del Comportamiento, 4(1), 31-43.

Katsuki, H., Yukitoshi, I., \& Zorumski, C. F. (1997). Noradrenergic regulation of synaptic plastici- ty in the hippocampal CA1 region. Journal of Neurophysiology, 77, 3 013-3 020.

LaLumiere, R. T., Buen, T. V., \& McGaugh, J. L. (2003). Post-training intra-basolateral amygdala infusions of norepinephrine enhance consolidation of memory for contextual fear conditioning. Journal of Neuroscience, 23, 6754-6758. doi: 0270-6474/03/236754-05

Lee, H. J., Berger, S. Y., Stiedl, O., Spiess, J., \& Kim, J. J. (2001). Posttraining injections of cathecolaminergic drugs do not modulate fear conditioning in rats and mice. Neuroscience Letters, 303, 123-126. doi: 10.1016/S0304-3940(01)01733-5 Lennartz, R. C., Hellems, K. L., Mook, E. R., \& Gold, P. E. (1996). Inhibitory avoidance impairments induced by intra-amygdala propranolol are reversed by glutamate but not glucose. $B e$ havioral Neuroscience, 110, 1033-1039. doi: 10.1037//0735-7044.110.5.1033

Liang, K. C., Juler, R. G., \& McGaugh, J. L. (1986). Modulating effects of post-training epinephrine on memory: Involvement of the amygdala noradrenergic system. Brain Research, 368, 125-133. doi: 10.1016/0006-8993(86)91049-8

Liang, K. C., McGaugh, J. L., \& Yao, H. (1990). Involvement of the amygdala pathways in influence of posttraining amygdala norepinephrine and peripheral epinephrine on memory age. Brain Research, 508, 225-233. doi: 10.1016/00068993(90)90400-6

Lucki, I., Ward, H. R., \& Frazer, A. (1989). Effect of $1 \mathrm{mg}$ chlorophenyl-piperazine and $1 \mathrm{mg}$ trifluoromethylphenyl) piperazine on locomotor activity. Journal of Pharmacology and Experimental Therapies, 249, 155-164.

McGaugh, J. L. (2000). Memory: a century of consolidation. Science, 287, 248-251. doi: 10.1126/ science.287.5451.248

McGaugh, J. L., Cahill, L., \& Roozendaal, B. (1996). Involvement of the amygdala in memory storage: interaction with other brain systems. Proceedings of the National Academy of Sciences, 93, 13 508-13514. 
Middlemeis, D. (1984). Stereoselective blockade at $[3 \mathrm{H}] 5-\mathrm{HT}$ binding sites and at the 5HT autoreceptor by propranolol. European Journal of Pharmacology, 101, 289-293. doi: 10.1016/0014-2999(84)90173-0

Miranda, M.I., Rodríguez-García, G., Reyes-López, J.V., Ferry, B., \& Ferreira, G. (2008). Differential effects of $\beta$-adrenergic receptor blockad in basolateral amygdala or insular cortex on incidental and associative taste learning. $\mathrm{Neu}-$ robiology of Learning and Memory, 90, 54-61. doi: 10.1016/j.nlm.2008.01.004

Morris, R. W., Westbrook, R. F., \& Killcross, A. S. (2005). Reinstatement of extinguished fear by beta-adrenergic arousal elicited by a conditioned context. Behavioral Neuroscience, 119, 1662 1 671. doi: 10.1037/0735-7044.119.6.1662

Mueller D., Porter J. T., \& Quirk, G. J (2008). Noradrenergic signaling in infralimbic cortex increases cell excitability and strengthens memory for fear extinction. Journal of neuroscience, 28(2), 369-375. doi: 10.1523/JNEUROSCI.3248-07.2008

Murchinson, C. F., Zhang, X. Y., Zhang, W. P., Ouyang, M., Lee, A., \& Thomas, S. A. (2004). A distinct role for norepinephrine in memory retrieval. Cell, 117, 131-114. doi: 10.1016/S00928674(04)00259-4

Nielson, K. A., Czech, D. A., \& Laubmeie, K. K. (1999). Chronic administration of propranolol impairs inhibitory avoidance retention in mice. Neurobiology of Learning and Memory, 71, 248-257. doi: 10.1006/nlme.1998.3873

Ouyang, M. \& Thomas S. A. (2005). A requirement for memory retrieval during and after long-term extinction learning. Proceedings of the National Academy of Sciences, 102, 9347-9352.

Pitman, R. P., Sanders, K. M., Zusman, R. M., Healy, R. A., Cheema, F., Lasko, N. B., Cahill, L., \& Orr, S. P. (2002). Pilot study of secondary prevention of posttraumatic stress disorder with propranolol. Biological Psychiatry, 51, 189142. doi: 10.1016/S0006-3223(01)01279-3
Pontecorvo, M., Clissold, D., White, M., \& Ferkany, J. (1991). N-Methyl-D-aspartate antagonists and working memory performance: Comparison with the effects of scopolamine, propranolol, diazepam, and phenylisopropyladenisone. $B e-$ havioral Neuroscience, 105, 521-535.

Prut, L. \& Belzung, C. (2003). The open field as a paradigm to measure the effects of drugs on anxiety-like behaviors: a review. European Journal of Pharmacology, 463, 3-33. doi: 10.1016/S00142999(03)01272-X

Przybyslawski, J., Roullet, P., \& Sara, S. J. (1999). Attenuation of emotional and nonemotional memories after their reactivation: role of beta adrenergic receptors. Journal of Neuroscience, 19(15), 6623-6628. doi: 0270-6474/99/196623

Rex, A., Voigt, J. P., Voits, M., \& Fink, H. (1998). Pharmacological evaluation of a modified openfield test sensitive to anxiolytic drugs. Pharmacology Biochemistry and Behavior, 59, 677-683. doi: 10.1016/S0091-3057(97)00461-9

Robinson, M. J. \& Franklin, K. B. (2007). Central but not peripheral beta-adrenergic antagonism blocks reconsolidation for a morphine place preference. Behavioral Brain Research, 182, 129-134. doi: 10.1016/j.bbr.2007.05.023

Robinson, M. J. \& Franklin, K. B. (2010). Reconsolidation of a morphine place preference: impact of the strength and age of memory on disruption by propranolol and midazolam. Behavioral Brain Research, 213(2), 201-207. doi: 10.1016/j. bbr.2010.04.056

Robinson, M. J., Ross, E. C., \& Franklin K. B. (2011). The effect of propranolol dose and novelty of the reactivation procedure on the reconsolidation of a morphine place preference. Behavioural Brain Research, 216, 281-284. doi: 10.1016/j. bbr.2007.05.023

Rodriguez-Romaguera, J., Sotres-Bayon, F., Mueller, D., \& Quirk, J. G. (2009). Systemic propranolol acts centrally to reduce conditioned fear in rats without impairing extinction. Biological 
Psychiatry, 65, 887-892. doi:10.1016/j. biopsych.2009.01.009

Roozendaal, B., de Quervain, D. J. F., Schelling, G., \& McGaugh, J. L. (2004). A systemically administered $\beta$-adrenoceptor antagonist blocks corticosterone-induced impairment of contextual memory retrieval in rats. Neurobiology of Learning and Memory, 81, 150-154. doi: 10.1016/j.nlm.2003.10.001

Ruetti, E., Justel, N., Mustaca, A., \& Boccia, M. (2014). Corticosterone and propranolol's role on taste recognition memory. Pharmacology, Biochemistry and Behavior, 127, 37-41. doi: org/10.1016/j.pbb.2014.09.013

Sara, N., Datta, H., \& Sharma P. L. (1991). Effects of morphine on memory: interactions with naloxone, propranolol and haloperidol. Pharmacology, 42, 10-4.

Sara, S. J., Vamkov, A., \& Hervé, A. (1994). Locus Coeruleus-evoked responses in behaving rats: a clue to the role of noradrenalin in memory. Brain Research Buletin, 35, 457-465. doi: 10.1016/0361-9230(94)90159-7

Schneider, A. M, Simson, P. E., Atapattu, R. K., \& Kirby, L. G. (2011). Stress-dependent impairment of passive-avoidance memory by propranolol or naloxone. Pharmacology, Biochemistry and Behavior, 98, 539-543. doi: 10.1016/j. pbb.2011.03.005

Sprouse, S. J. \& Aghajanian, G. K. (1986). Propranolol blocks the inhibition of serotonergic dorsal raphe cell firing by 5 -HTIA selective agonists. European Journal of Pharmacology, 128, 295298. doi: 10.1016/0014-2999(86)90782-X

Sternberg, D. B. \& Gold, P. E. (1985). Effects of $\alpha$ and $\beta$ adrenergic receptor antagonists on retrograde amnesia produced by frontal cortex stimulation. Behavioral and Neural Biology, 29, 289-30. doi: doi: 10.1016/S0163-1047(80)90164-8

Stuchlik, A., Petrasek, T., \& Vales, K. (2009). A dose-response study of the effects of pre-test administration of beta-adrenergic receptor antagonist propranolol on the learning of active place avoidance, a spatial cognition task, in rats. Behavioural Brain Research, 200, 144-149. doi: 10.1016/j.bbr.2009.01.010

Sun, H., Mao, Y., Wang, J., \& Ma, Y. (2011). Effects of beta-adrenergic antagonist, propranolol on spatial memory and exploratory behavior in mice. Neuroscience Letters, 498, 133-137. doi: doi:10.1016/j.neulet.2011.04.076

Suresh, V. \& Steven, R. (2003). Drugs for preventing migraine headaches in children. Cochrane Database of Systematic Reviews, 4, CD00276. doi: 10.1002/14651858.CD00276

Thomas, J., Moody, T. D., Makhinson, M., \& O’Dell, T. J. (1996). Activity-dependent beta-adrenergic modulation of low frequency stimulation induced LTP in the hippocampal CA1 region. Neuron, 17, 475-482. doi: 10.1016/S08966273(00)80179-8

Tuinstra, T. \& Cools, A. R. (2000). High and low responders to novelty: effects of adrenergic agents on regulation of accumbaI dopamine under challenged and non-challenged conditions. Neuroscience, 99, 55-64. doi: 10.1016/ S0306-4522(00)00139-1

Vaiva, G., Ducrocq, F., Jezequel, K., Averland, B., Lestavel, P., Brunet, A., \& Marmar, C. R. (2003). Immediate treatment with propranolol decreases posttraumatic stress disorder two months after trauma. Biological Psychiatry, 54, 947-949. doi: 10.1016/S0006-3223(03)00412-8

Winder, D. G., Martin, K. C., Muzzio, I. A., Rohrer, D., Chruscinski, A., Kobilka, B., \& Kandel, E. R. (1999). ERK plays a regulatory role in induction of LTP by theta frequency stimulation and its modulation by beta-adrenergic receptors. Neuron, 24, 715-726. doi: 10.1016/ S0896-6273(00)81124-1

World Health Organization (WHO). (2013). Who Model List of Essential Medicines-18th list. WHO Medicines web site. Recuperado de http://www. who.int/medicines/publications/essentialmedicines/en/index.html 
Zhang, J., He, J., Chen, Y. M., Wang, J. H., \& Ma, Y. Y. (2008). Morphine and propranolol co-administration impair consolidation of Y-maze spatial recognition memory. Brain Research, 1230 , 150-157. doi: 10.1016/j.brainres.2008.06.061

Zhang, G., Herborg, N., Ásgeirsdóttira, S. J., Cohenc, A. H., Munchowa, M. P., Barreraa, R. W., \& Stackman Jr. (2013). Stimulation of serotonin $2 \mathrm{~A}$ receptors facilitates consolidation and extinction of fear memory in C57BL/6 $\mathrm{J}$ mice. Neuropharmacology, 64, 403-413 doi: 10.1016/j.neuropharm.2012.06.007

Fecha de recepción: junio 2, 2015

Fecha de aceptación: febrero 1, 2016 
